15. Сластенин В.А. К вопросу о профессионализме учителя общеобразовательной школы // Советская педагогика. 1973. № 5. С. 72-80.

16. Безрукова В.С. Педагогика. Проективная педагогика: учебное пособие для инженерно-педагогических институтов и индустриально-педагогических техникумов. Екатеринбург, 1996. 344 с.

17. Колесникова И.А. Педагогическое проектирование: учебное пособие для высших учебных заведе- ний. М.: Издательский центр «Академия», 2005. $288 \mathrm{c}$.

18. Сластенин В.А. Субъектно-деятельностное содержание профессионально-личностного развития учителя // Профессионализм педагога: компетентностный подход в образовании: мат-лы междунар. науч.-практ. конф. М.: МАНПО, 2011. С. 3-18.

19. Новые ценности образования: тезаурус для учителей и школьных психологов. № 1. М., 1995. 101 с.

\title{
MASTER STUDENTS' SCIENTIFIC RESEARCH DESIGN AS A TEACHER TRAINING PROFESSIONAL DEVELOPMENT FACTOR
}

(C) 2018

Smolyar Antonina Ivanovna, doctor of pedagogical sciences, professor, head of Music Department

Zogol Svetlana Gennadyevna, candidate of pedagogical sciences, associate professor of Music Department Samara State University of Social Sciences and Education (Samara, Russian Federation)

Abstract. The paper proves that master students' scientific research is the essence for teacher training professional development. The authors describe the model, substantiate approaches to master students' scientific research position and content understanding based on their analyses of the experience of master students' scientific research predictive model representation. Methodologically these are activity and research approaches; and their implementation principles are practice-oriented educational process principle, activity and creative content of education principle and the educational process personalization principle. The paper exposes to light the experience of master students' scientific research organization pedagogical conditions implementation (scientific research building into the theoretical and practical courses of master degree program study; its presentation as a means of master student's personal pedagogical experience and professional activity evaluation and correction; master student's personal pedagogical experience use as a base in the process of theoretical course study; the connection of theoretical courses, practical trainings, work on master's thesis). The paper highlights peculiarities of master students' scientific research organization process. These peculiarities are: the search of leading pedagogical experience, academic research organization; teaching practice and theoretical courses educational program composition on the basis of research and education problems solving and projects implementation; the educational research and scientific research practical training content connection with master's thesis subject; simulation training as a method of enquiry and transformation of pedagogical reality and etc.

Keywords: pedagogical professional competency; teacher training professional development; scientific research; design; master's degree program; teacher training; model; scientific approaches and principles; scientific research organization process; scientific research organization pedagogical conditions; academic research; theoretical courses; practical training; simulation; master's thesis.

\section{ИЗУЧЕНИЕ ВОЗМОЖНОСТЕЙ АДАПТИВНОЙ ПРОГРАММЫ ПО ФИЗИЧЕСКОЙ КУЛЬТУРЕ «ОТ БОЛЕЗНИ К ЗДОРОВЬЮ» В РЕАЛИЗАЦИИ ОЗДОРОВИТЕЛЬНОГО МОТИВА СТУДЕНТОВ С ОСЛАБЛЕННЫМ СОСТОЯНИЕМ ЗДОРОВЬЯ}

(C) 2018

Черкашина Анна Георгиевна, кандидат психологических наук, доцент кафедры физического воспитания

Самарский государственный соииально-педагогический университет (2. Самара, Российская Федераиия)

Аннотация. Каждый студент с ослабленным состоянием здоровья сталкивается в повседневной жизни с проблемой сохранения и укрепления своего здоровья. Период обучения в вузе связан с увеличением учебной нагрузки, понижением двигательной активности, совмещением учебной деятельности и подработками и т.п. В статье обсуждаются результаты констатирующего и двухгодичного формирующего эксперимента на занятиях адаптивной программой по физической культуре «От болезни к здоровью» по изменению внутренней картины здоровья с целью реализации оздоровительного мотива студентами с ослабленным состоянием здоровья. Внутренняя картина здоровья - это сумма знаний, чувств и особенностей поведения в отношении собственного здоровья. Итоги исследования ВКЗ дают учащимся с ослабленным состоянием здоровья возможность всестороннего видения собственной модели здоровья сквозь призму когнитивного, эмоционального, телесного и поведенческого аспектов, а также представляют собой основу для формирования у студентов мотивов по укреплению своего здоровья. Процесс формирующего эксперимента нацелен на изменение внутренней картины здоровья студентов, через восполнение пробелов в когнитивном, телесном и эмоциональном аспектах, и расширение поведенческих возможностей в здоровьесберегающей деятельности.

Ключевые слова: оздоровительный мотив; внутренняя картина здоровья; информационный/когнитивный аспект; эмоциональный аспект; телесный/телесный аспект; поведенческий/мотивационный аспект; студенты с ослабленным состоянием здоровья; констатирующий эксперимент; формирующий эксперимент; личностная активность студентов; проблема сохранения и укрепления здоровья. 


\section{Введение}

Для каждого человека здоровье представляет собой несомненную ценность. Только когда у человека все в порядке со здоровьем, у него есть силы и вдохновение для дел, общения и творчества. Любое недомогание непременно влияет на человека, его самочувствие и работоспособность. Наличие здоровья обусловливает не только осуществление жизненных целей, личностное развитие, но непосредственно и само существование человека, продолжительность и качество его жизни. По мнению Л.В. Куликова, «отношение к здоровью, выраженное в предрасположенности к сохранению или растрачиванию здоровья, может рассматриваться как личностное качество. В отношении к здоровью у многих людей скрыты серьезные противоречия» [1]. Г.Ю. Козина, В.Я. Шклярук, изучая студенческую среду, продолжают: «Студенты, зная о ценности здоровья, тем не менее не осознают необходимости обеспечивать мотивацию здорового поведения, не владеют навыками здорового стиля жизни, нуждаются в приобретении знаний и практического опыта в области укрепления своего здоровья» [2; 3].

Каждый студент с ослабленным состоянием здоровья сталкивается в повседневной жизни с проблемой сохранения и укрепления своего здоровья. Период обучения в вузе связан с увеличением учебной нагрузки, понижением двигательной активности, совмещением учебной деятельности и подработками и т.п. Как указывает Т.Ю. Мысина, «студенческая среда относится к ситуациям повышенных требований, психических нагрузок и перегрузок. Все это затрудняет деятельность студентов в организации собственной физической активности оздоровительного характера. Для сохранения и укрепление здоровья необходимо изменить отношение студентов к своему здоровью - оно должно стать ценностным» [4].

\section{Методы и организация исследования}

В Самарском государственном социально-педагогическом университете (СГСПУ) на кафедре физического воспитания студенты с отклонениями в состоянии здоровья занимаются в специальной медицинской группе по программе адаптивной физической культуры «От болезни к здоровью». Одной из основHblx задач занятий физической культурой со студентами спецгруппы в данной программе выступает формирование компетенции по развитию субъективной активности в отношении действий по укреплению своего здоровья, т.е. формирование ценности здоровья. Преподаватель физической культуры на занятиях со спецгруппой не ограничивает студентов в движениях, а помогает им найти альтернативу движениям, опираясь на их индивидуальное самочувствие, ориентируясь на процесс удовольствия от движения, а не на результат. Упор на занятиях в специальной группе ставится на том, как переживается здоровье в собственном теле, и что каждый студент с ослабленным здоровьем может сделать для улучшения своего состояния. Не погружаться в болезнь, а смещать акцент к выздоровлению. Конечной целью занятий со студентами с отклонениями в состоянии здоровья по программе «От болезни к здоровью» следует рассматривать включение физической активности в повседневную жизнь студентов с целью укрепления здоровья [5].
Для достижения цели на занятиях преподаватель по физической культуре ориентирует студентов на реализацию оздоровительного мотива.

В силу вышесказанного иелью нашего исследования является изучение возможностей адаптивной программы по физической культуре «От болезни к здоровью» в реализации оздоровительного мотива студентов с ослабленным состоянием здоровья. Объект исследования: внутренняя картина здоровья студентов с ослабленным состоянием здоровья. Предмет исследования: изменения внутренней картины здоровья студентов с ослабленным состоянием здоровья. Методы исследования: анализ литературных источников, опрос-анкета по мотивам занятий физической культурой В.И. Ильинича [6], самоописание внутренней картины здоровья (ВКЗ), пилотажное исследование, констатирующий и формирующий эксперимент, контент-анализ и качественный анализ полученных результатов.

\section{Результаты и их обсуждение}

Реализация оздоровительного мотива со студентами экспериментальной группы по программе «От болезни к здоровью» происходит в три этапа.

\section{Первый этап - пилотажное исследование}

и констатирующий эксперимент.

В начале первого года обучения со студентами специального отделения контрольной $(\mathrm{n}=53)$ и экспериментальной группы $(\mathrm{n}=64)$ было проведено $n u$ лотажное исследование, в котором применялась опрос-анкета по мотивам занятий физической культурой В.И. Ильинича [6]. Его целью является выяснение места оздоровительного мотива в иерархии мотивов занятий физической культурой. Результаты данного опроса-анкеты отражены на рис. 1.

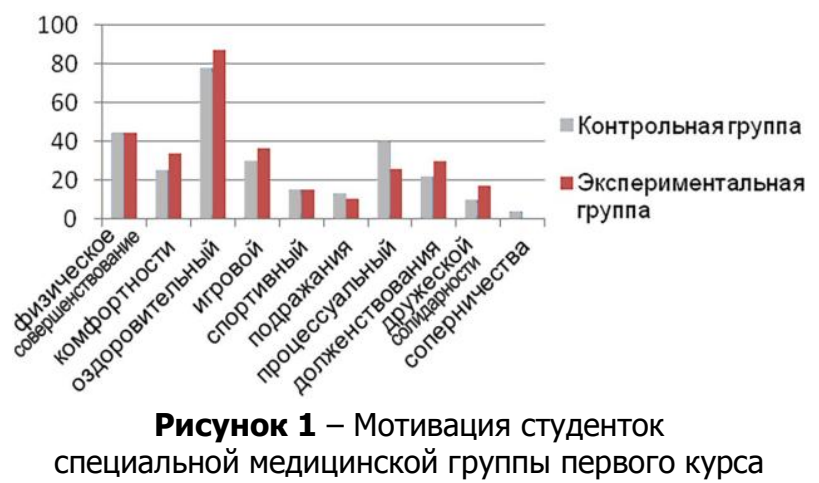

Рисунок 1 иллюстрирует иерархию мотивов студенток специальной медицинской группы первого курса контрольной и экспериментальной группы. Можно увидеть, что выбор мотивов занятий физической культуры схож у студенток как контрольной, так и экспериментальной группы. Как в одной, так и в другой группе оздоровительный мотив $(78,1 \%$ и $87,2 \%$ ) имеет наибольшую побудительную силу и является действующим. Студентки осознают связь между занятиями физической культурой и здоровьем и влиянием занятий физической культуры на состояние здоровья и выбирают оздоровительный мотив как побуждающий к занятиям. Таким образом, оздоровительный мотив на занятия физической культурой для данной группы студенток является наиболее актуальным.

Установленное положение оздоровительного мотива в контрольной и экспериментальной группе в нашем исследовании является контрольной точкой 
для наблюдения в результате последующего формирующего эскперимента.

Для реализации оздоровительного мотива на занятиях физической культурой необходимо создать условия для того чтобы «мотив стал осознанным, чтобы знание перешло в действие, а значит, студент будет сам проявлять активность без внешнего контроля в отношении своего здоровья [5]». Для этого на занятиях физической культурой со студентами специального отделения экспериментальной группы проводится констатирующий эксперимент по изучению внутренней картины здоровья (ВКЗ). Поскольку «основной функцией ВКЗ является регуляция деятельности индивида в отношении его поведения, направленного на поддержание здоровья и противостояние болезни [5; 7]».

Впервые понятие «внутренняя картина здоровья» было упомянуто В.М. Смирновым и Т.Н. Резниковой, которые рассматривали ее «как своеобразный эталон здорового человека, или здорового органа, или части тела и т.д. Этот эталон может быть достаточно сложным и включать различные элементы в виде образных представлений и логических обобщений» [8]. В.Е. Каган уточняет и утверждает, что «понятие «здоровье» - это не только антоним понятия «болезнь», но и мера отклонения от физиологической, статистической и индивидуальной нормы. Человек - субъект этой индивидуальной нормы - так или иначе знает, что такое здоровье и соотносит с этим свое актуальное состояние. Человек считает себя больным только лишь, когда его переживания своего состояния не вписываются в его «внутреннюю картину здоровья» и, напротив, представления о здоровье могут быть настолько широкими, что обнимают широкий круг патологических состояний» [9]. В.А. Ананьева рассматривает внутреннюю картину здоровья как «совокупность интеллектуальных представлений здоровья индивидуума, комплекс эмоциональных переживаний и ощущений, а также его поведенческих реакций [10]».

ВКЗ включает в себя следующие аспекты: информационный/когнитивный, сенситивный/телесный, эмоциональный и поведенческий/мотивационный.

Информационный/когнитивный аспект - это «рациональная часть ВКЗ, представляет собой совокупность субъективных или мифологических умозаключений, мнений о причинах, содержании, возможных прогнозах, а также оптимальных способах сохранения, укрепления и развития здоровья (в целом, все то, что формирует систему верований человека). Фиксирует личностный опыт заболевания и выздоровления, так и определенные теоретические представления. Наличие этого аспекта проявляется в сформированной субъективной модели здоровья [11]».

Эмоциональный аспект характеризуется «эмоциональным реагированием на проявления здоровья, его иногда обозначают как эстетика здоровья [11]».

Сенсорный/телесный аспект «представлен различными сенсорными сигналами организма. Складываясь преимущественно на основе «схемы тела», сенсорный компонент дополняется аудиальными и визуальными сигналами. Человек не только чувствует, ощущает, но «видит» и «слышит» свое здоровье [11]».

Поведенческий/мотивационный аспект характеризуется «совокупностью усилий, стремлений, конкретных действий человека, обусловленных его си- стемой верований и направленных на достижение субъективно-значимых целей. Отражает потребность (далеко не во всем осознанную) быть здоровым, степень ответственности за свое здоровье, готовность к определенным самоограничениям для сохранения и развития здоровья. Это этическая сторона здоровья [11]».

Таким образом, внутренняя картина здоровья это сумма знаний, чувств и особенностей поведения в отношении собственного здоровья.

Проведение констатирующего эксперимента необходимо для того, «чтобы вывести на уровень осознания представления и отношения к здоровью [5]». Так как здоровье - это некое виртуальное понятие, важно определить для каждого студента с ослабленным состояние здоровья, как он понимает, что такое «здоровье», как здоровье переживается в теле, эмоциях, мыслях и в поведении. Таким образом, задача констатирующего эксперимента сделать цель (укрепление здоровья) видимой. Студенты получают домашнее задание разобрать и письменно изложить собственные компоненты внутренней картины здоровья. Далее в группе обсуждается внутренняя картина здоровья каждого. В итоге констатирующего эксперимента на основе обобщения опыта работы каждого, групповой дискуссии и контент-анализа нами была описана ВКЗ студентов с отклонениями в здоровье $(n=64)$ [5]. В кратком изложении ВКЗ3 выглядит следуюшим образом:

«В информационном/когнитивном аспекте здоровья мы рассматривали представления и знания студентов о своем здоровье и способах его сохранения и поддержания [5]». Можно выделить несколько видов ответов.

Самые распространенные ответы: а) Здоровье это когда ничего не беспокоит, ничего не болит; б) Здоровье - это гармония телесного, духовного и социального. Студенты озвучивают определение, данное ВО3 [12].

Менее распространенные ответы: а) Здоровье это субъективное переживание; б) Здоровье - это позитивный настрой и эмоциональное благополучие; в) Здоровье - это взаимосвязь тела и эмоций.

Таким образом, констатирующий эксперимент по когнитивному аспекту внутренней картины здоровья позволил нам выявить две группы ответов в понимании здоровья. По нашему мнению, группа распространенных ответов отражает усредненное знание общества в целом о здоровье, выраженное в миниатюре студенческой группы, без включения личностной осознанности. Группа менее распространенных ответов выражает личный опыт студентов в переживании здоровья, который отражается в осознанном понимании взаимосвязи между хорошим самочувствием и эмоциями, субъективным и позитивным настроем.

Сенситивный/телесный аспект предполагает «описание ощущений в теле, которые переживаются во время здоровья [5]». Участники группы обращают внимание на признаки проявления здоровья, личные двигательные возможности и комфортные движения. К «телесным признакам здоровья были отнесены: отсутствие боли, расслабленное, легкое, свободное, без мышечных зажимов тело [5]». Студенты озвучили, что им было трудно работать с телесным аспектом внутренней картины здоровья, так как непривычно 
говорить о телесных ощущениях здоровья, поскольку нет умения и личного опыта наблюдения за ними.

В эмоциональном аспекте мы исследуем чувства, которые переживаются когда есть здоровье. Полюс здоровья можно представить переживаниями радости, удовольствия, счастья, гармонии, любви, оптимизма, желания творить. Студенты подчеркивают, что положительные эмоции - это неотъемлемая часть здоровья, а хорошее отношение к чему-либо это очень важно. «Озвучивание в группе данных эмоций здоровья позволяет каждому подключить свое отношение и переживание к собственному здоровью, а также разделить эти чувства вместе со всей группой и ощутить поддержку группы [5]». Эмоциональный компонент затрагивает личностную включенность и необходим для того, чтобы более глубоко прикоснуться к осознанию необходимости укреплять свое здоровье и настроиться на позитивную веру в собственные возможности это сделать.

«Поведенческий компонент предполагает действия, необходимость изменения поведения и привычного образа жизни, актуализацию деятельности по возвращению и сохранению здоровья [5]». Студенты озвучили следующие свои действия, направленные на укрепление здоровья: ведение ЗОЖ, правильное питание, рациональный режим сна, в достаточной мере двигательная деятельность. «Но, как оказалось, эти действия являются формальными, так как студенты не смогли ответить на вопросы: «Что значит вести ЗОЖ? Сколько часов необходимо спать каждому? Что значит правильное питание и какое оно у вас? Что значит достаточная физическая активность и какая она у вас?». В большинстве своем студенты не знают, что конкретно нужно делать для того, чтобы укреплять свое здоровье [5]».

Далее, студентам был задан вопрос: «Что вам мешает следить за своим здоровьем?».

Можно выделить несколько причин /оправданий бездействия по осуществлению оздоровительной деятельности студентов с ослабленным состоянием здоровья и сгруппировать их следующим образом, это:

1. Неэффективная организация режима труда и отдыха. В данную группу причин входят: а) дефицит времени на регулярный прием пищи, полноценный сон, самостоятельные занятия физической культурой, внимание к себе; б) лень; в) восприятие здоровья как данности.

Анализируя эту группу причин, студенты совместно с преподавателем обогащаются опытом друг друга по поиску необходимого количество времени для сна, питания, регулярных занятий физической культурой, а также выясняют, какие способы помогают преодолеть лень и каждый день уделять внимание своему здоровью.

2. Препятствия, вызванные болезненными симптомами и последствиями болезни. К данной группе причин можно отнести: а) медицинские противопоказания; б) сезонные обострения заболевания; в) страх за последствия своих действий; г) противоречия. Примерный ответ: «Когда я занимаюсь физическими упражнениями, у меня не болит голова, не появляются черные точки перед глазами, я чувствую себя самым счастливым человеком на Земле. У меня отличное настроение, я готова действовать. Сразу же проблема не кажется такой огромной. Но постоянно появляются мысли, что это состояние недолговечно, и скоро оно сменится унылым настроением, вызванным болью в голове и в глазах».

Обсуждение данной группы помех помогает участникам разобраться в понимании медицинских противопоказании к физической активности, а именно, что можно делать и в каком количестве, с какой нагрузкой и т.п., а также устранить пробелы знаний, которые приводят к страху за последствия своих действий. Помимо этого, поделиться друг с другом опытом по облегчению сезонных обострений болезни и способами сохранять позитивный настрой вне занятий физической культуры.

Таким образом, анализ поведенческого аспекта внутренней картины здоровья помогает студентам с ослабленным здоровьем осознать собственные действия и бездействия и предложить конкретные, личностно-значимые способы изменения поведения для сохранения и укрепления здоровья.

Описание ВКЗ дает возможность студентам спецгруппы всесторонне рассматривать собственную модель здоровья сквозь призму когнитивного, эмоционального, телесного и поведенческого аспектов, также представляют собой основу для формирования у студентов мотивов по укреплению своего здоровья. Следует отметить, что описанная выше ВКЗ не является статичной и универсальной для всего студенческого контингента. Напротив, внутренняя картина здоровья динамична, и следующий этап формирующего эксперимента необходимо строить в соответствии с особенностями ее содержания.

\section{Второй этап - формирующчий эксперимент}

Его целью выступает изменение внутренней картины здоровья студентов специальной медицинской группы, через восполнение пробелов в когнитивном, телесном и эмоциональном аспектах, и расширение поведенческих возможностей в здоровьесберегающей деятельности.

Полученные данные ВКЗ в результате констатирующего эксперимента позволили нам поставить следующие задачи формирующего этапа.

В информационном / когнитивном аспекте необходимо расширить знания студентов:

- об индивидуальных противопоказаниях и показаниях к движению с учетом заболевания, обоснованности и необоснованности медицинских запретов к физической активности;

- об индивидуальном способе замены запрещенных / противопоказанных движений альтернативными/комфортными движениями, физическими упражнениями, физической активностью и т.п.;

- об индивидуальном и конкретном влиянии физических упражнений на здоровье как замена медикаментозного лечения;

- о взаимосвязи разных видов физической активности с эмоциональным настроем, с физическим самочувствием;

- о технически правильном выполнении ОРУ, двигательных умений и т.п.;

- о возможностях движения и положения собственного тела в пространстве;

- о жизнедеятельности основных систем организма и причин нарушения в их функционировании;

- о допустимых телесных ощущениях при выполнении физических нагрузок схожих с болезненными 
симптомами (увеличение ЧСС и учащение дыхания, мышечные боли и судороги, тошнота, головокружение, усталость и т.п.);

- о позитивных психологических установках в отношении собственной физической активности, здоровьесберегающей деятельности.

В телесном /сенситивном аспекте необходимым дополнением будет:

- обучение навыкам осознанного внимания и наблюдения за собственным самочувствием в процессе разных видов и интенсивности физической активности;

- развитие индивидуального репертуара движения с включением: движений всеми частями тела, движениями тела в пространстве, движениями на разных уровнях, динамических качеств движений по Р. Лабану [13, с. 85-102];

- осознание собственных двигательных ограничений и возможностей;

- осознание личных телесных ощущений переживания здоровья / хорошего самочувствия;

- практическое выстраивание связи между комфортными и некомфортными физическими действиями и ощущениями;

- наблюдение за индивидуальными допустимыми телесными ощущениями при выполнении физических нагрузок схожих с болезненными симптомами (увеличение ЧСС и учащение дыхания, мышечные боли и судороги, тошнота, головокружение, усталость и т.п.) и их различение.

В эмоциональном аспекте важно:

- создать безопасную, принимающую, безоценочную обстановку на занятии;

- акцентировать внимание каждого не на конкуренцию друг с другом, а на конкуренцию с самим собой (вчерашним, сегодняшним, завтрашним);

- развивать умение понимать свое эмоциональное состояние, его изменение в зависимости от физического самочувствия или вида физической активности;

- ориентировать на движения, приносящие удовольствие, «мышечную радость», комфорт;

- повышать уверенность в собственных силах через выполнение ранее не освоенных упражнений или движений, которые технически выполнялись неправильно, а также посредством создания индивидуальных ситуаций успеха (двигательных достижений / преодолений);

- поддерживать позитивный настрой (установку) на занятие с использованием образных и выразительных движений.

В поведенческом аспекте научить:

- находить время в течение дня на себя, на осознание своего самочувствия, состояния;

- находить время на достаточное количество сна;

- находить время на регулярные приемы пищи в течение дня;

- находить время на регулярные занятия физическими упражнениями;

- брать ответственность за свои действия и их последствия в сохранении и укреплении здоровья;

- стратегиям поведения в стрессовых ситуациях;

- навыкам расслабления;

- ставить индивидуальные цели на каждое занятие по физической культуре;
- самоподдержки посредством индивидуальных позитивных установок;

- применять индивидуальные физические упражнения по улучшению своего самочувствия;

- вырабатывать стратегии гибкого поведения посредством развития разнообразного репертуара движения как способ избежания стереотипного поведения;

- анализировать и вносить коррективы в результаты собственной деятельности на занятиях физической культуры и в повседневной жизни по укреплению своего здоровья;

- использовать полученные знания и умения по укреплению своего здоровья в повседневной жизни.

Таким образом, поставленные выше задачи по четырем аспектам ВКЗ выступили как руководство к действию и реализовывались на занятиях физической культуры со студентами специального отделения экспериментальной группы в течение двух лет обучения.

\section{Третий этап - констатирующий}

эксперимент и пилотажное исследование

Целью этого этапа выступает анализ изменений в поведении студентов экспериментальной группы к своему здоровью. Для этого студентам предлагается домашнее задание по написанию итогового эссе по теме: «Интеграция опыта по реализации оздоровительного мотива». В данном эссе студенты описывают свой личный опыт, опираясь на изменения, которые произошли у них во внутренней картине здоровья, анализируют свои успехи и неудачи, свою активность в собственной здоровьесберегающей деятельности. Затем в группе проводится совместное обсуждение личного опыта каждого и группы в целом, и подводятся итоги групповой работы.

С помощью контент-анализа нами было проанализировано содержание итоговых эссе студентов по теме «Интеграция опыта по реализации оздоровительного мотива». Можно выделить несколько конкретных видов изменения поведения студенток специальной группы в отношении своего здоровья.

Соблюдение режима питания и сна. Примерный ответ студентов: «Сейчас пытаюсь соблюдать режим питания и специальную диету и режим сна.

Понимание взаимосвязи между эмоциональным и телесным самочувствием. Примерный ответ студентов: «Мое психологическое здоровье связано с физическим, и если мои эмоции под контролем, то под контролем и собственное самочувствие».

Практическое выстраивание связи между физическими действиями, приводящими к комфортным и некомфортным ощущениям. Примерный ответ студентов: «Облегчаю себе подъем по лестнице с помощью дыхания, это помогает мне контролировать пульс и не перенапрягаться».

Ответственность за свои действия и их последствия в сохранении и укреплении здоровья. Примерный ответ студентов: «Я стала больше следить за своим самочувствием во время болезненных обострений, чем раньше. При появлении симптомов недомогания я увеличиваю продолжительность сна, чаще выхожу на прогулки, больше употребляю витамины, стараюсь делать хотя бы минимальные физические нагрузки, употреблять достаточное количество воды». 
«Практическое выстраивание связи между физическими действиями, приводящими к комфортньм и некомфортным ощущениям [5]». Примерный ответ студентов: «Я научилась бороться с болью из-за плоскостопия во время бега и ходьбы. Во время бега двигаю стопой с носка на пятку, а хожу на тыльной стороне стопы. Когда нужно долго стоять, например, ждать автобус, то я распределяю свой вес тела на две стопы равномерно, ищу три точки опоры (большой палец, мизинец, пятка), это помогает мне меньше уставать. Все эти движения и поиски опоры постепенно переходят в автоматизированный режим.

Осознание собственных двигательных ограничений и возможностей. Примерный ответ студентов: «Теперь я осознаю, что могу двигаться, несмотря на ограничения врачей, просто дозируя нагрузку и следуя своим ощущениям, прекращая движения при появлении дискомфортных ощущениях».

Регулярные занятия физическими упражнениями. Примерный ответ студентов: «Я выполняю дома, как минимум, три раза в неделю несложную тренировочную программу, в которой, помимо разминки и упражнений для приведения мышц в порядок, присутствуют упражнения, направленные на снижение болей в спине, вызванных сколиозом».

Индивидуальная замена противопоказанных движений альтернативными /комфортными движениями. Технически правильное выполнение ОРУ, двигаmельных умений и m.n. Примерный ответ студентов: «Я начала искать альтернативу тем движениям, выполняя которые чувствовала себя не очень хорошо. Так я научилась правильно дышать, благодаря этому бег дается мне значительно легче, чем раньше. Обычно я старалась его избегать. А в этом семестре я даже 12-минутный бег выдержала и не сказала бы, что это было чем-то непосильно сложным для меня».

Использование полученных знаний и умений по укреплению своего здоровья в повседневной жизни. Примерный ответ студентов: «Теперь я стараюсь не воспринимать свое здоровье как данность. Даже будучи здоровой, я стараюсь создать все возможные условия, способствующие укреплению и сохранению здоровья, и это меня очень вдохновляет, наполняет надеждой, верой в лучшее».

Анализ и коррекция результатов собственной деятельности на занятиях физической культурь и в повседневной жизни по укреплению своего здоровья. Примерный ответ студентов: «Я смогла оценить эффективность принимаемых мною мер по улучшению моего здоровья, а также разработала стратегию дальнейших действий. Теперь поняла, что состояние моего организма можно изменить не только медикаментами, но и физическими тренировками, а также контролем негативных эмоций. Я поняла, что мое здоровье - это очень важная, первостепенная вещь. Теперь моя задача не борьба с болезнью, а сохранение своего здоровья и его улучшение».

Понимание индивидуального и конкретного влияния физических упражнений на здоровье как замень медикаментозного лечения. Примерный ответ студентов: «На данный момент значительно меньше стали боли в области шеи и спины, я думаю, именно благодаря растягивающим и укрепляющим упражнениям». Личностное осознание важности заботы о своем здоровье. Примерный ответ студентов: «До института я не задумывалась о своем здоровье. Зна- ла, что нужно чаще спортом заниматься, но никогда не проводила такого глубокого самоанализа ВКБ и ВКЗ».

Поддержание позитивного настроя на здоровьесберегаюшую деятельность. Примерный ответ студентов: «Я считаю, что путь к здоровью начинается с правильного отношения к нему, поэтому для укрепления намерений быть здоровой в первую очередь я буду обращаться к своим записям об эмоциональном компоненте здоровья».

Осознанное внимание к своему самочувствию 6 течение дня. Примерный ответ студентов: «Я стала уделять немного больше внимания своему здоровью. Стала следить за тем, как я себя веду в течение дня, стала следить за тем, чтобы не тратить излишнюю энергию на лишние движения, стала принимать контрастный душ, следить за тем, что я ем. Я верю в то, что мои знания в этой области помогут сделать мою жизнь лучше».

Выделенные нами виды изменения поведения показывают, что в процессе формирующего эксперимента на занятиях физической культурой были созданы возможности для реализации у студентов с ослабленным состоянием здоровья оздоровительного мотива. Студенты экспериментальной группы предпринимают конкретные, личностно-значимые действия по сохранению и укреплению своего здоровья и занимают активную субъектную позицию в здоровьесберегающей деятельности.

Повторное проведение опрос-анкеты по мотивам занятий физической культурой В.И. Ильинича в конце второго года обучения студентов экспериментальной и контрольной группы подтверждает сделанные нами выводы (см. рис. 2).

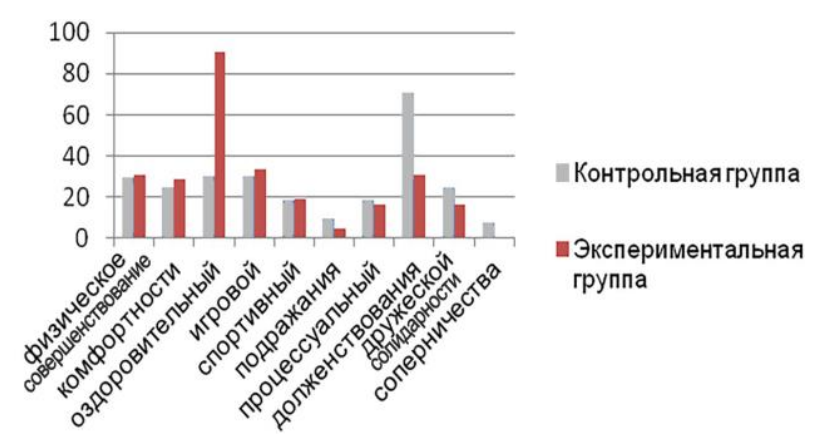

Рисунок 2 - Мотивация студенток

специальной медицинской группы второго курса

Согласно рис. 2 произошли изменения в иерархии выбора мотивов занятий физической культуры у студенток контрольной группы. Мотив долженствования (посещение ради зачета) занял первое место у $70 \%$ опрошенных. Оздоровительный мотив, который на первом курсе у студенток контрольной группы занимал лидирующее место $(78,1 \%)$, в конце второго курса снизился до $30 \%$. Противоположная картина у экспериментальной группы. Оздоровительный мотив остался на лидирующем месте на первом курсе и немного повысился до 90\% от первоначальных 87,2\%.

\section{Выводы}

В процессе занятий физической культурой по программе «От болезни к здоровью [5]» студенты экспериментальной группы не потеряли понимания актуальности оздоровительного мотива в отличие от студентов контрольной группы, которые занимались по общей программе по дисциплине «Физическая 
культура для лиц с ограниченными возможностями здоровья». Таким образом, разработанная нами программа «От болезни к здоровью» предоставляет для студентов с ослабленным состоянием здоровья условия и возможности для реализации оздоровительного мотива на занятиях физической культурой. По нашему мнению, включение в программу дисциплины «Физическое воспитание» (для студентов с ограниченными возможностями здоровья) формирующего эксперимента по изменению внутренней картины здоровья является необходимым звеном в формировании личностно-значимого поведения по укреплению своего здоровья.

\section{Список литературы:}

1. Куликов Л.В. Психогигиена личности. Вопросы психологической устойчивости и психопрофилактики. СПб.: Питер, 2004. С. 18-19.

2. Козина Г.Ю. Концептуальная модель воздействия социальных факторов на формирование здоровья человека // Х Социологические чтения преподавателей, аспирантов и студ. Пенза, 2008. С. 69-82.

3. Шклярук В.Я. Самосохранительное поведение в молодежной среде // Социологические исследования. 2008. № 10. С. 139-142.

4. Мысина Т.Ю. Формирование ценностного отношения к здоровью у студентов вуза // Вестник СаГА. Серия: Психология. 2011. № 2. С. 46-57.

5. Черкашина А.Г. Описание внутренней картины болезни и здоровья на занятиях физической культурой со студентами спецмедгрупп // Адаптивная физическая культура. 2017. № 1 (69). С. 45-51.

\section{FEATURES STUDY \\ OF PHYSICAL EDUCATION ADAPTIVE PROGRAM «FROM SICKNESS TO HEALTH» WITHIN THE HEALTH MOTIVE OF STUDENTS WITH THE IMPAIRED HEALTH STATUS} (C) 2018

Tcherkashina Anna Georgievna, candidate of psychological sciences, associate professor of Physical Education Department Samara State University of Social Sciences and Education (Samara, Russian Federation)

Abstract. Each student with the weakened state of health collides in a daily life with a problem of preservation and strengthening of the health. The period of training in high school is connected with increase in an academic load, downturn of impellent activity, overlapping of educational activity and part time job, etc. In this paper there are results of an ascertaining and a two-year forming experiment within the Adaptive Program «From sickness to health» (The discipline is Physical Education). The aim is to change the internal picture of students with the impaired health status. The internal picture of health is a set of cognitive knowledge, perceptions, and descriptions of human health of the person and also complex emotional experiences, sensations and behavioral reactions. Study results of the internal picture of health give students with the impaired health status an opportunity of all-round vision of health through a prism of cognitive, emotional, corporal and behavioral aspects, as well as they promote personal student's health strengthening activity (a health motive).

Keywords: health motive; internal picture of health; information/cognitive aspect; emotional aspect; corporeal aspect; behavioral/motivational aspect; students with impaired health status; ascertaining experiment; forming experiment; personal student's activity; preservation and health strengthening problem. 